\title{
Problematizando o eurocentrismo e desconstruindo o racismo por meio de práticas pedagógicas decoloniais e interculturais
}

\author{
Probleming eurocentrism and unconstructing racism through decolonial and \\ intercultural pedagogical practices
}

\author{
Odair de Souza ${ }^{1}$ \\ Elison Antonio Paim ${ }^{2}$
}

\begin{abstract}
Resumo: O artigo conceitua e problematiza o eurocentrismo derivado da colonialidade (do poder, do saber e do ser) como gerador do racismo (estrutural e institucional) contra povos africanos, afro-brasileiros e indígenas no Brasil, em todas as esferas sociais, particularmente na escola e propõem a construção de práticas pedagógicas decoloniais e interculturais como possibilidades de desconstrução desse processo. Apresentamos fragmentos da pesquisa $A$ educação para as relações étnicorraciais no ensino de história: memórias e experiências de professoras da educação básica dissertação submetida ao Mestrado Profissional em Ensino de História- Profhistória da Universidade Federal de Santa Catarina. Dialogamos com narrativas de professoras coletadas na forma de entrevistas orais gravadas e depois organizadas na perspectiva metodológica de Walter Benjamin construindo mônadas.
\end{abstract}

Palavras-chave: eurocentrismo - racismo decolonialidade - ensino de História

\begin{abstract}
The article conceptualizes and problematizes the Eurocentrism derived from coloniality (of power, knowledge and pain to be) as a generator of racism (structural and institutional) against African, Afro-Brazilian and indigenous peoples in Brazil, in all social spheres, particularly at school. and proposes the construction of decolonial and intercultural pedagogical practices as possibilities of deconstruction of this process. We present fragments of the research Education for ethnicracial relations in history teaching: memories and experiences of teachers of basic education dissertation submitted to the Graduate Program in History Teaching of the Federal University of Santa Catarina. We dialogue with narratives of teachers collected in the form of recorded oral interviews and then organized in the methodological perspective of Walter Benjamin building monads.
\end{abstract}

Keywords: eurocentrism - racism decoloniality - history teaching.

\section{Para iniciar uma conversa}

Escribo gritando. Gritando escribo. Lxs que me conocen saben que nunca - o muy rara vez - grito; mi manera de expresar los sentimientos de frustración, indignación, rabia, dolor y horror es otra. No obstante, ahora no puedo contener este chillido que nace desde muy adentro y que sale por los poros y orificios de mi cuerpo como estruendo. Los órganos en su conjunto y liderado por el alma y el corazón, gritan iNO! gritan iDIGNIDAD! y gritan

\footnotetext{
${ }^{1}$ Bacharel e licenciado em História pela Universidade do Sul de Santa Catarina ( UNISUL), especialista em Mídias na Educação pela Universidade Federal do Rio Grande ( FURG) e Mestre em Ensino de História. E-mail: professorodair2014@gmail.com

${ }^{2}$ Professor permanente do Programa de Pós-Graduação em Educação (PPGE) e do Mestrado Profissional em Ensino de História (Profhistória-UFSC) da Universidade Federal de Santa Catarina. Doutor em Educação pela Unicamp e Mestre em História pela PUC-SP. Membro dos grupos de pesquisa Pameduc (UFSC), Rastros (USF) e Kairós (UNICAMP). E-mail: elison0406@gmail.com
} 
¡VIDA Mi grito es producto y reflejo de la acumulación de un sentir! (WALSH, 2017, p. 17).

Desde os primeiros tempos do Brasil - colônia que povos de diversas etnias africanas foram forçadamente e violentamente obrigados a vir para cá na condição de escravizados, trazendo consigo uma série de experiências, memórias, conhecimentos, saberes e dizeres que foram ressignificados e fazem parte do dia-a-dia do povo brasileiro. Porém, mesmo com a participação das populações negras e indígenas na composição da população brasileira e com o fim da escravidão - abolida oficialmente em 1888 - a sociedade brasileira é racista, pois é um legado desse processo escravagista que permanece até a atualidade. Este racismo gritante na sociedade brasileira se manifesta de diversas formas (físicas, simbólicas e psicológicas. Concordamos com Passos (2011) que no Brasil este racismo tem assumido,

variadas formas de expressão, das mais sutis as mais explicitas, das individualizadas as institucionalizadas, em todas elas alcançando uma eficiência letal no comprometimento das subjetividades atingidas principalmente pela violência simbólica de seus mecanismos de submissão e controle. Em nosso cotidiano há uma lista enorme de ações e intencionalidades que se configuram e se amalgamam no universo das práticas consideradas discriminatórias ou preconceituosas e que estas, quando ligadas a critérios de fenotipia como a cor da pele, a tessitura dos cabelos, os traços corporais que denotam pertencimento a um determinando grupo etnicorracial - negros, quilombolas, indígenas, ciganos - ou os religiosos, principalmente no Brasil das religiões de matrizes indígenas e africanas - são consideradas racistas. (p.4- 5).

Elucidativo deste racismo anunciado pelo autor acima é a última publicação do Atlas da Violência no Brasil divulgando que

de cada 100 pessoas que sofrem homicídios no Brasil, 71 são negras. Jovens e negros do sexo masculino continuam sendo assassinados todos os anos como se vivessem em situações de guerra. [...]. Foi constatado que em todas as unidades da federação, com exceção do Paraná, os negros com idade entre 12 e 29 anos apresentavam mais riscos de exposição à violência que os brancos na mesma faixa etária. Em 2012 o risco relativo de um jovem negro ser vítima de homicídio era 26,6 vezes maior que um jovem branco. (CERQUEIRA; LIMA; 2017, pp. 30-31)

Notícias recentes indicam que às perseguições as religiões de matriz africana são as que mais crescem no Brasil ${ }^{1}$. Na imprensa falada e escrita quase que diariamente são veiculados casos de discriminações ${ }^{2}$ e racismo contra pessoas negras. Um dos casos bastante divulgado, para além de tantos outros, foi o caso da torcedora ${ }^{3}$ que num jogo de futebol ofendeu e xingou o goleiro Aranha com palavras racistas.

Percebe-se assim o quanto a desigualdade racial ${ }^{4}$ e o racismo estão manifestos em vários aspectos da sociedade brasileira: na mídia, nos espaços públicos, no esporte, enfim, em vários 
momentos de suas vidas o/a negro/negra, em sua maioria, possivelmente já sofreram algum tipo de racismo e discriminação, e isto está relacionado ao racismo estrutural da sociedade brasileira, (ALMEIDA, 2018).

Mas afinal, o que é racismo? Como o racismo brasileiro se perpetua no cotidiano, nos relacionamentos interpessoais, nas instituições sociais e, particularmente nas escolas? Como as escolas têm trabalhado esses temas? Qual tem sido o papel da escola para senão extinguir, pelo menos atenuar o racismo em seu ambiente?

Para responder aos questionamentos acima propostos, necessita-se antes de tudo compreender o que é o racismo e como ele se perdura, sobretudo nas instituições sociais, e em especial nas escolas. Almeida (2018, p.25) ao conceituar racismo cita que

racismo é uma forma sistemática de discriminação que tem a raça como fundamento e que se manifesta por meio de práticas conscientes ou inconscientes que culminam em desvantagens ou privilégios para indivíduos a depender do grupo racial ao qual pertence

Ainda segundo Almeida há três concepções de racismo: individualista, institucional e estrutural. Abordo neste texto o racismo institucional, pois a escola enquanto instituição, em muitos casos, é estimuladora de racismo por meio de gestos e atitudes de seus integrantes e especialmente por meio de conteúdos e suas formas de abordá-los. Para tanto, consideramos como racismo institucional "aquele que é tratado nas instituições como resultado do funcionamento das instituições, que passam a atuar em sua dinâmica que confere ainda que indiretamente desvantagens e privilégios a partir da raça”. (ALMEIDA, 2018, p. 29). Uma concepção que complementa essa pode ser encontrada em Souza (2011) é a partir do conceito de racismo institucional que se pode encontrar práticas efetivas de combate a este racismo. Para o autor, “o conceito de Racismo Institucional refere-se a políticas institucionais que mesmo sem o suporte da teoria racista de intenção produzem conseqüências desiguais para os membros de diferentes categorias raciais”. (REX, 1987, apud SOUZA, 2011, p. 79)

Porém, esse racismo estrutural e institucional da América Latina em geral, e do Brasil em particular, tem uma origem histórica e isto remonta a colonização da América após 1492. Fundamentamo-nos no pensamento do sociólogo peruano Anibal Quijano para dizer que os europeus ao colonizarem a América instituíram o racismo enquanto pedra angular de poder. Segundo ele, “a colonialidade é um dos elementos constitutivos e específicos do padrão mundial do poder capitalista” e foi fundada na “imposição de uma classificação racial/étnica da população do mundo com pedra angular do dito padrão de poder e opera em cada um dos planos, 
âmbitos e dimensões materiais e subjetivas da existência social cotidiana e da escala social” 5 . (tradução nossa). (QUIJANO, 2007, p. 93).

\section{Uma conversa sobre decolonialidade}

Assim, entendemos que este racismo construído historicamente a partir da colonização da América deixou marcas profundas em todos os aspectos da vida social, tanto do colonizado quanto do colonizador. Estas marcas, segundo Quijano, podem ser desdobradas em colonialidade do poder, do saber e do ser. Para ele, os europeus ao conquistarem a América, fazem-na não somente do ponto de vista militar, mas também conquistam e introduzem subjetividades nas populações dominadas.

Esta colonialidade do poder mundial ao se impor, subalterniza, invisibiliza povos e culturas, saberes e epistemes. Oliveira (2013, p. 50) considera que

O colonizador destrói o imaginário do outro, invisibilizando-o e subalternizando-o enquanto reafirma o próprio imaginário. Assim, a colonialidade do poder reprime os modos de produção de conhecimento, os saberes, o mundo simbólico, as imagens do colonizado e impõem novos. Opera-se então a naturalização do imaginário do invasor europeu, a subalternização epistêmica do outro não europeu e a própria negação e esquecimento de processos históricos não europeus. Essa operação pode-se realizar sob várias formas como pela sedução pela cultura colonialista e o fetichismo cultural que o europeu cria em torno de sua cultura realizando uma verdadeira aspiração pela cultura européia por parte dos sujeitos subalternizados. Portanto, o eurocentrismo não é a perspectiva cognitiva somente do europeu, mas também daqueles do conjunto dos educados sob sua hegemonia.

Esta citação, um pouco prolongada, propõe refletirmos como essa colonialidade nos invade, nos lesiona de maneira brutal, pois nos força a acreditar que o único modelo de pensamento válido é o europeu. Portanto, apesar de algumas resistências, esta perspectiva descarta os conhecimentos e saberes dos povos indígenas, dos povos afro-brasileiros, dos quilombolas, dos ciganos, povos do campo, ribeirinhos, entre outros. Dessa maneira, a colonialidade do poder traz em seu bojo a colonialidade do saber. Ou seja, esta colonialidade do saber fundada pela cultura e o mundo acadêmico europeu perpassa todas as instituições do mundo acadêmico latino-americano, chega às escolas e sistemas educativos de todos os países. Sobre esta colonialidade do saber, temos que subverter, pois segundo Oliveira (2012, p. 54) “a colonialidade do saber operou a inferioridade de grupos humanos não europeus do ponto de vista da divisão racial do trabalho. Do salário, da produção cultural e dos conhecimentos”.

Para além, da colonialidade do poder, do saber, a colonialidade também impôs a colonialidade do ser, onde os povos subalternizados impregnaram de tal forma a episteme 
europeu que parece difícil radicalizar e romper com essas formas de conhecimento. Oliveira (2012, p. 59) exemplifica dizendo que em outros termos a colonialidade do ser refere-se à experiência vivida da colonização e seus impactos na linguagem, que responde sobre a necessidade de se explicitar sobre os efeitos da colonialidade na experiência de vida e não somente na vida dos colonizados.

Estas colonialidades (do poder, do saber e do ser) estudadas pelo grupo Modernidade/Colonialidade, ${ }^{6}$ constituído por pesquisadores latino-americanos, de alguma maneira impactou e impacta-nos, pois de algum modo fomos, somos e continuamos violentados por essas colonialidades em todos os espaços: educativos, midiáticos, redes sociais, livros, revistas, igreja, etc.

Como consequência direta dessas colonialidades, os colonizadores europeus estabeleceram em quase todo o globo terrestre o eurocentrismo. Este impôs que a única matriz cultural aceita em todos os âmbitos sociais e, particularmente na educação é a européia. O eurocentrismo se naturaliza e se impõe como algo dado, acabado, pronto. No entanto, assim como a colonialidade e o racismo em todas as suas vertentes, o eurocentrismo também é uma construção histórica. É uma maneira própria de ver e perceber o mundo e está alicerçado numa perspectiva européia de vida e de existência. Desconsideram desta perspectiva conhecimentos, saberes, valores, ciências de outros povos e etnias como as indígenas e africanas por exemplo. Neste sentido esta perspectiva ideológico-epistemológica pervertida pelo racismo esforça-se por naturalizar e reforçar valores ideológicos e epistemes europeus como se fossem os únicos válidos e aceitos universalmente.

Quando estudamos a Revolução industrial, por exemplo, “esquecemos -nos” que na retaguarda desse acontecimento europeu estão as milhares de mãos de escravizados nas colônias inglesas norte americanas que trabalhavam no plantio, coleta e envio do algodão para as fábricas inglesas. Carvalho (2017, p. 302) menciona que “a revolução industrial alavancou um movimento orquestrado com o seqüestro de “africanos” usados como mão de obra escrava para usurpar as riquezas “descobertas” nas colônias americanas”

Quando estudamos a Revolução Francesa ou o Iluminismo não deduzimos que por trás da famosa frase "liberdade, igualdade, fraternidade”, lema da Revolução Francesa inspirada no Iluminismo, nas diferentes colônias dos países europeus existia uma população numerosa de pessoas escravizadas, destituídas, portanto da tal liberdade, igualdade e fraternidade. Carvalho (2017, p. 306) nos informa que no período das revoluções burguesas “o total de populações 
escravizadas nas Américas, no ano de 1700, era de aproximadamente 330.000 aumentando para quase três milhões no ano de 1800 e atingindo mais de seis milhões no ano de 1850”. Assim, Quijano (2005, p. 115) nos provoca a pensarmos que,

o eurocentrismo é uma perspectiva de conhecimento iniciada na Europa Ocidental no século XVII cuja constituição esteve "associada a específica secularização burguesa do pensamento europeu e a experiência e as necessidades do padrão mundial do poder capitalista colonial/moderno, eurocentrado estabelecido a partir da América.

Também Barbosa (2008, p.47) em diálogo com Samir Amin define o eurocentrismo como

a crença generalizada de que o modelo de desenvolvimento europeu ocidental seja uma fatalidade (desejável) para todas as sociedades e nações. [...], uma ideologia, cuja genealogia deveria ser buscada no Renascimento, remontando a gênese do capitalismo como sistema mundial [...], como modelo de produção, realmente existente.

Entendemos, portanto, o eurocentrismo como ideologia e paradigma que durante muito tempo - invisibilizou e silenciou a presença e a história de povos e culturas africanas, afrobrasileiras e indígenas no Brasil. Invisibilidade esta presente em todos os aspectos societários da população brasileira, mas especialmente na educação, foco das análises neste texto.

\section{Uma conversa sobre tentativas de decolonizar os silêncios na educação}

Porém, desde há muito tempo, particularmente a partir da década de 1970, quando da fundação do Movimento Negro Brasileiro Contemporâneo (PEREIRA, 2010) que a história e cultura do povo africano e suas diásporas tem pautadas as discussões da inclusão de histórias e culturas no currículo escolar, via lei pelos poderes legislativos, como importante instrumento de luta política e epistêmica. Isso via legislativos das Câmaras de Vereadores ${ }^{7}$, das Assembleias Legislativas dos Estados e do Congresso Nacional.

Uma das primeiras tentativas de viabilizar a histórias e culturas dos afro-brasileiros, africanos e suas diásporas no currículo escolar em âmbito nacional se deu na constituição de 1988 que em seu inciso LXII e no artigo 248, § $1^{\circ}$ menciona que “o ensino de história do Brasil levará em conta as contribuições das diferentes culturas e etnias para a formação do povo brasileiro”. Outra formulação legislativa também foi inserida na Lei de Diretrizes e Bases da Educação Nacional (LDB) em 1996 que em seu artigo 26, § $4^{\circ}$ cita que “o ensino de história do Brasil levará em conta a contribuição das diferentes culturas e etnias para a formação do povo brasileiro, especialmente das matrizes indígenas, africanas e europeias”. Porém, segundo Costa (2011) a LDB não deu a devida importância a história e cultura dos povos afro-brasileiros, 
africanos e suas diásporas bem como a educação para as relações étnico-raciais. No que diz respeito as relações étnico-raciais a LDB silenciou, pois:

Não há evidências de que o processo de elaboração dessas diretrizes tenha se orientado por fundamentos epistemológicos capazes de fornecer elementos necessários a elaboração de um imaginário social que rejeite as antigas concepções raciais. Não situou na agenda da educação escolar o combate ao racismo, embora este se faça presente em todas as instâncias da sociedade brasileira. Ignorou não somente o disposto constitucional quanto ao ensino da História do Brasil levar em conta a contribuição das diferentes culturas e etnias como também iniciativas neste sentido que já se encontrava em curso [...] Um silêncio que no tocante a educação escolar não implicou apenas na negação dos negros brasileiros, como também indicou numa explícita tentativa de pelo silêncio, negar a própria existência dos sujeitos de modo a renegar-lhes à indiferença, torná-los invisíveis e imperceptíveis, ou seja, inexistentes enquanto sujeitos-históricos sociais. (COSTA, 2011, p.92)

Apesar das sucessivas tentativas do Movimento Negro Brasileiro de colocar as histórias e culturas do povo negros no currículo escolar - este só veio a se efetivar de fato, via legislação com a homologação e publicação da lei 10.639, no governo do presidente Lula, em 03 de janeiro de $2003^{8}$. E posteriormente complementada pela Resolução $n^{\circ} 001 / 2003$ e pelo parecer $n^{\circ}$ 003/2004 que instituiu as Diretrizes Curriculares Nacionais para a Educação das Relações Étnico-raciais e para o Ensino de História e Cultura Afro-brasileira e Africana, documento este que indica os principais caminhos a serem trilhados para quem quiser fazer uma efetiva educação para as relações étnico-raciais em sala de aula.

Entretanto, apesar de a lei 10.639/2003 já ter mais de 14 anos, pesquisas, de autores/as como Oliveira (2010), Santos (2010), Dias (2011), Pereira (2011), Paula (2013), Borges (2014), Passos (2014) tem relatado a não implementação desta lei nos sistemas públicos e privados de ensino, bem como pelos docentes em suas respectivas salas de aula.

\section{Uma conversa com professores sobre relações étnicorraciais na escola}

Para apurar melhor como está acontecendo a implementação da Lei nas escolas, apresentamos uma pesquisa desenvolvida por Souza (2018) no âmbito do Mestrado Profissional em Ensino de História da Universidade Federal de Santa Catarina denominada A educação para as relações étnico-raciais no ensino de História: memória e experiências de professoras da educação básica. O qual utilizou aportes teóricos em Walter Benjamin numa interface com autores decoloniais procurou por meio de entrevistas feita com quatro professoras da Escola de Educação Básica Luiz Carlos Luiz, no município de Garopaba, Santa Catarina, investigar e identificar por meio de suas memórias e experiências como está a efetivação da lei no ensino de história e educação para as relações étnico-raciais? Quais as possibilidades e/ou dificuldades na implementação da mesma? Como pensam a lei 10.639/2003 no contexto da sala de aula? 
Como a lei tem sido usada para o combater o preconceito, o racismo e discriminação? A partir de narrativas, gravadas em áudio, foram feitos recortes que foram ouvidos, transcritos e procedeu-se a montagem de mônadas que trazem em seu bojo elementos para a discussão de como está acontecendo as práticas educativas com a educação para as relações étnico-raciais em sala de aula.

As tessituras monadológicas permitem ao leitor conhecer as professoras e suas memórias e experiências a partir delas mesmas. Portanto, da perspectiva de metodologia de análise não falamos nem sobre e nem para as professoras. Falamos com as professoras e ouvimos suas narrativas. Neste sentido, o que são memórias e experiências das professoras e suas articulações com a educação para as relações étnico-raciais? Quais relações podem ser feitas? Quais parâmetros utilizar?

Nas entrevistas com os docentes podemos perceber em suas memórias e experiências muito mais que uma docência técnica, racional, instrumental, mas sim a preocupação com uma racionalidade estética (MATOS, 1989) na qual os sentimentos, os desejos, os sonhos, as sensibilidades na relação ao trabalho na perspectiva da educação para as relações étnico-raciais puderam ser captadas. A vontade de fazer diferente é grande. Entretanto, muitos obstáculos são colocados entre o sonho e a realidade como o conhecimento fragmentado, a disciplinarização, a falta de tempo, a racionalidade instrumental, a falta de espaços para compartilhar experiências, entre outros. Neste sentido, os docentes vivem aquilo que Walter Benjamin (2012, p. 123 - 128) chamou de “pobreza das experiências comunicáveis”. E acrescentamos o que Larossa (2017, p. 25) contribui ao afirmar que

a experiência, a possibilidade de que algo nos aconteça ou nos toque, requer um gesto
de interrupção, um gesto que é quase impossível nos tempos que correm, requer parar
para pensar, parar para olhar, para escutar, pensar mais devagar e escutar mais devagar,
para sentir, sentir mais devagar, demorar-se nos detalhes, suspender a opinião,
suspender o juízo, suspender a vontade, suspender o automatismo da ação, cultivar a
atenção e a delicadeza, abrir os olhos e os ouvidos, falar sobre o que nos acontece,
aprender a lentidão, escutar os outros, cultivar a arte do encontro, calar muito, ter
paciência e dar-se tempo e espaço.

Mas, mesmo neste tempo de correria e de pobreza de experiência, as professoras pararam para relatar suas memórias e experiências. Mas o que seria memória, na concepção benjaminiana? E experiência? Qual o sentido destes conceitos em interface com a educação para as relações étnico-raciais?

Dialogando com Walter Benjamin, filósofo berlinense, no texto “Infância em Berlin por volta de 1900” (BENJAMIN, 2012) evidenciamos que a memória não é algo parado no tempo. 
Memória é dinamicidade de produção de conhecimento, memórias que se entrecruzam em diversos espaços e tempos e nos levam a nos encontrar e a nos (re) encontrar com outros sujeitos, com suas diferentes maneiras de ser e entender o mundo.

Ao trabalhar com memórias por vias de práticas educativas, promovemos encontros com outros sujeitos e conosco mesmo para que possamos indicar outras possibilidades de educação, de história, de ensino de história e de ensino para a educação para as relações étnico-raciais. Segundo Galzerani (2008, p. 25) o trabalho com a educação e o ensino com base nas memórias [...] tem possibilidade e ao mesmo tempo a busca do afastamento da racionalidade instrumental, técnica no que diz respeito à construção do conhecimento histórico educacional, isto é, a não hierarquização dos saberes. Representam questionamentos em relação às abordagens metodológicas, globalizantes, homogeinizadoras, compartimentabilizadas, dicotômicas, maniqueístas, mecânicas, distantes das experiências - os quais tem prevalecido nas práticas de conhecimentos acadêmicos nesta modernidade tardia ou ainda potencializam a busca de maior imbricação entre pesquisa/ensino, micro e macro histórias, memórias e histórias, fundamentos psicopedagógicos e historiográficos, teorias e experiências, presente/passado/futuro, Logos e Eros.

Também Paim, Pereira e Freire (2018, p. 18) reiteram que para Benjamin

Memórias são carregadas de conhecimentos, saberes, sentidos, significados e sensibilidades, relacionam-se com o vivido. Memória é também esquecimento, apaziguamento com o passado. A (re) memória é sempre relacionada com o presente, já que é um entrecruzamento dialogal entre tempos e espaços e vozes distintas. É uma memória que não é só racional. É de um sujeito inteiro, prenhe de incompletudes. Portanto, humana. Memória é vida. Possibilidade de experiência vivida. Na rememoração amplia-se a possibilidade da vida.

Para um diálogo conceitual com a experiência, retomamos o texto de Benjamin (2012), "Experiência e Pobreza”, no qual nos possibilita observar que as experiências deixam de ser relevantes para as sociedades humanas na modernidade. A narrativa deixou de ser uma viagem com suas histórias, fantasias, gestos e sensibilidades. A sociedade moderna empobreceu significativamente a experiência humana, esta, por sua vez, foi reduzida ao movimento das vivências individuais - automatizadas, mecânicas, extremamente racionalizadas, destituídas de sentimentos e sensibilidades. É na experiência coletiva, portanto, que encontramos sentidos mais complexos, abertos e gratificantes para a vida.

Os fragmentos de entrevistas relativos à educação para as relações étnico-raciais foram analisados na forma de mônadas (BENJAMIN, 1984). Para Galzerani em diálogo direto com o pensamento de Walter Benjamin as mônadas são "como miniaturas dos significados mais explosivo deste projeto de educação dos sentidos como centelhas capazes de nos instigar a capacidade de reflexão” (2013, p. 100). Assim, procuramos flagrar os sucessos, os insucessos, 
as esperanças, os sonhos dos docentes em mônadas que foram construídas em relação a temática em estudo, bem como a vontade de superação do racismo, dos preconceitos e das discriminações. Assim, nas mônadas abaixo trouxemos pequenos trechos capazes de fornecer elementos para uma análise das possibilidades ou impossibilidades da implementação da lei 10.639/2003, bem como a educação para as relações étnico-raciais nas salas de aula, relacionadas com suas memórias e experiências em tempos de estudantes e de docência.

\section{Eu tomei a decisão que queria me especializar na área de África}

[...] Eu já falei que usava bastante. Mas eu tinha muita admiração pela História. [..] Um dos primeiros professores, onde eu decidi, o que eu queria estudar foi o Paulão - Paulo Lúcio. Nas primeiras aulas que ele deu sobre cultura africana, eu já me encantei já me decidi. Isso foi no segundo semestre. Eu já me decidi. O que eu queria estudar na minha monografia. Eu tomei a decisão que queria me especializar na área de África. (Mauricélia Albuquerque, 2017).

\section{Pra quem já trabalha com este tema não é algo novo}

Teve sim. Claro que sim. Tanto na pedagogia. Tenho curso de pedagogia na UNIASSELVI. [..] Tem um livro de cultura africana. A nossa disciplina é à distância. A gente tem um encontro semanal. Então a gente estuda a disciplina, faz um paper e apresenta. Funciona assim. Tem um livro sobre cultura africana. [...] Ajudou sim. Então na verdade pra quem já trabalha com este tema não é algo novo né. Mas eu acredito que pra quem não trabalha em sala de aula seria algo novo. Na verdade, me ajudou muito mais para estudar para fazer concurso, porque em relação ao trabalho em sala de aula eu já faço, então não foi algo assim, então agora eu vou começar a fazer. (Marilete Pinto de Oliveira, 2017).

\section{Não teve absolutamente nada relacionado à África, cultura afro-brasileira e educação para as relações raciais. Nada mesmo!}

Na minha licenciatura, o que eu lembro é que tínhamos um caderno chamado Caderno de História da África. Era bem assim mesmo: História da África e daí a gente trabalhou um mês, então, esse caderno História da África. Foi também, só um mês e eu acho que foi o único que teve relação com esse tema aqui. Esse caderno funcionava assim, uma aula por semana. A professora monitora era professora de história, daí a gente tirava dúvida com a professora monitora. Ela era muito inteligente, que tirava muito as nossas dúvidas. A gente não aprofundava muito caderno em casa, mas quando chegava à sala de aula, aproveitava muito que ela tinha para nos dizer. Mas, em geral, a gente tinha era que estudar mesmo no caderno em casa e tinha só duas aulas para tirar essas dúvidas. Duas aulas nesse sentido seriam mais ou menos assim: duas manhãs ou duas tardes em média 3 horas e meia cada aula. [...] Não? Absolutamente! Passou longe disso. Esse tema é um tema bem abrangente. Até mesmo após a nossa conversa semana passada, eu tive que dar uma pesquisada, assim para ver mais ou menos o que era pra poder tá fornecendo essa entrevista para ti hoje. E aí, dá para ver que parece que quanto mais a gente estuda, mais coisa parece. Então, tá bem longe! Tem que ser na verdade, uma especialização. Nesse tempo - da especialização, dá pra gente estudar e entender alguma coisa. [...] Então! Na minha pós-graduação, eu não me lembro de ter um tema específico. Assim, nenhum professor falando sobre temas específicos. Eu fiz a minha pós- 
graduação no tema chamado "Sociedade Contemporânea" envolvendo história, geografia e sociologia. Foi em 2013. Foi uma pós-graduação interdisciplinar, mas acabou focando mais na história mesmo e pelo fato de ter mais alunos de história no curso. Não teve absolutamente nada relacionado à África, cultura afro-brasileira e educação para as relações raciais. Nada mesmo! O que eu tive mesmo sobre isso foi só na graduação: famoso caderninho de "história da África” (Gilmar Gonçalves Machado, 2017).

\section{Se eu via algo de discriminação no momento, eu não deixava passar. Eu intervinha na hora!}

Bom, eu entrei na universidade em 2005. Na Universidade Federal de Santa Catarina. Na UFSC. Já era pós-lei 10.639/2003. Mas dentro da geografia, nunca houve nenhuma discussão. Aliás, mesmo sendo Universidade Federal e também para a licenciatura, deixa muito a desejar. Meu curso, na verdade é bacharel e licenciado, mas na universidade boa parte do curso é voltado para o bacharel e com mais meia dúzia de disciplina você tem o título de licenciatura. [...], Mas dentro da geografia, essas temáticas não foram contempladas. [...], Mas o que começou abrir mesmo meus olhos para essas questões foi principalmente o GDE ${ }^{9}$. Antes, eu tinha um posicionamento de muito de intervenções nessas questões. Por exemplo, se eu via algo de discriminação no momento, eu não deixava passar. Eu intervinha na hora. As discriminações de todas as formas. E aí com o GDE e os estudos, então eu comecei a enxergar mais situações que não enxergava. E aí eu disse: meu Deus, eu estou ficando louca. Tem pessoas que têm preconceito e discriminação em tudo. E daí eu abri os olhos para aquilo ali. E aí eu pensei: bom não dá para só intervir quando acontecer, mas tem que ser um trabalho sistemático. (Vanessa Elias, 2017)

Se a formação continuada em educação para as relações étnicorraciais e ensino de história e cultura africana e afro-brasileira praticamente não existe nas redes estaduais, os docentes terão sérias dificuldades em efetivamente implementar a referida lei em sala de aula e mais ainda para se orientar pelo que dispõe as Diretrizes.

As narrativas dos docentes evidenciam algumas temáticas que precisam ser problematizadas. A professora Marilete narrou que na minha "licenciatura em história teve um livro de cultura africana. A nossa disciplina é à distância. Ajudou sim”. E continua dizendo que "na verdade me ajudou muito mais para estudar, para fazer concurso porque em relação ao trabalho em sala de aula eu já faço” até porque segundo ela “o trabalho em sala de aula eu já faço”. Isto é interessante porque a professora, como experiência, está desenvolvendo no seu processo de ensino também novas aprendizagens para os estudantes e para si mesma, o que Tardif (2014) chama de “saberes docentes” e neste ocorre a apropriação de novos saberes, nós construímos e nos constituímos enquanto professores/as, num movimento constante de fazer e refazer-se, compondo o que Paim (2005) chama de "fazer-se professor".

Desenvolvemos saberes, valores e atitudes antirracistas e desconstruímos mitos, ideologias, enfim, cenários subalternizantes. Porém, é importante salientar que nossas 
experiências docentes não são suficientes para podermos trabalhar de maneira eficiente as posturas racistas e preconceituosas em salas de aula. Precisamos de bases teóricas conceituais consistentes para dar conta da nossa imensa tarefa e trabalharmos de acordo com a lei e as Diretrizes e, para além da nossa vontade pessoal de trabalharmos o tema, precisa ser um movimento que envolva toda a escola e insira todos/as neste movimento. Silva ao problematizar a educação para as relações étnico-raciais na escola de maneira isolada pondera que

assim, não é qualquer prática desenvolvida no espaço escolar que pode ser compreendida e apresentada como prática pedagógica daquela instituição. Portanto, o trabalho voluntário, pontual ou isolado de algumas professoras/es comprometidas/os com a discussão da história e cultura afro-brasileira e da educação para as relações étnico-raciais em sua atuação docente não configura a institucionalização da inclusão das temáticas nas instituições às quais estão vinculadas. (2011, p. 72)

O professor Gilmar que teve a mesma formação da professora anterior, ao falar do mesmo "Caderno da História da África” diz que não o ajudou absolutamente em quase nada para sala de aula. Diz ele ainda que foi o único caderno que tinha algo relacionado a este tema e que foi trabalhado durante um mês. Como as aulas eram à distância, com breves encontros para a retirada de dúvidas e a prova escrita, o tempo destinado aos estudos deste caderno foi insuficiente e ineficiente sequer para aprofundar nos estudos de história e cultura africana e afro-brasileira, salvo raras exceções, Segundo ele, "quando a professora tutora, que era de história e muito inteligente, tirava nossas dúvidas”. Estas narrativas dos docentes indicam que estas formações iniciais, sobretudo, as à distância não conseguiram atender a esta demanda de novos conhecimentos em tão pouco tempo e, por isso, são pouco aprofundados na graduação e ineficazes para fornecer elementos conceituais e teóricos para uma efetiva implementação da história e cultura africana e afro-brasileira em sala de aula.

A professora Mauricélia narrou que sequer há uma disciplina obrigatória de história da África nos cursos de licenciatura de geografia na UFSC, quando diz que, "mas, dentro da geografia, nunca houve nenhuma discussão [...], Mas, dentro da geografia, essas temáticas não foram contempladas”. Essa fala da professora problematiza que mesmo sendo o curso em uma universidade federal, e que seu curso se deu pós-lei 10.639/2003, não houve nenhuma disciplina ou sequer alguma discussão relacionada ao tema. Cabe sublinhar aqui outra problemática trazida pela professora: "porque tu imaginas, se eu, na Geografia, nas ciências humanas, não tive essa formação, imagina nas ciências exatas, nas ciências naturais, a formação é zero para essas questões”. Ou seja, de modo geral, não se está seguindo aquilo que preconiza a própria 
lei que é o estudo de história e cultura africana e afro-brasileira se darão no âmbito de "todo o currículo escolar”, preferencialmente em história, literatura brasileira e artes.

Portanto, o fato é, que se os docentes da educação básica não estão tendo a preparação adequada para lidar com estes temas. Estamos, assim, diante da colonialidade do saber. Para além, da colonialidade do saber, a colonialidade também impôs a colonialidade do ser, onde os povos subalternizados impregnaram de tal forma a episteme europeia que parece difícil radicalizar e romper com essas formas de conhecimento.

\section{Neste dia, para falar de mulher negra, ela fez questão de apresentar o trabalho}

No segundo ano do ensino médio a gente trabalha a questão da desigualdade social e quando a gente entra na questão desigualdade social, daí eu trabalho a desigualdade étnico-racial e as desigualdades de gênero. Ano passado os alunos fizeram apresentações de trabalho com temas específicos. Temas bem diversificados com relação à raça e a questão de gênero. Isso foi o ano passado, a gente fez seminários, eu passei texto com temas específicos que abordavam a temática de gênero e raça. Um dos resultados que foi muito interessante foi que uma estudante da escola que agora tá no terceiro, que ela é do Fortunato. Ela não apresenta trabalho. Ela é muito tímida, mas nesse dia, para falar da mulher negra, ela fez questão de apresentar o trabalho, porque fazia sentido para ela. Colocou-se no lugar, tipo eu tenho que falar, né? E foi assim bem legal. Foi um resultado bem interessante que eu achei desse trabalho que eu fiz. Esse ano, eu também estou fazendo. Estou trabalhando as desigualdades étnico-raciais, de gênero e aí eu deixo livre para trabalhar outros temas. Mas eu procuro focar na etnia negra. Porque é essa que está presente. Agora, eles estão elaborando curtas-metragens sobre esses temas. Eu deixei livre também. Eu trabalhei essas questões com eles e agora eles farão curtas-metragens de até 8 minutos sobre a questão da desigualdade social, desigualdade racial e desigualdade de gênero. Veio uma mulher moradora de Garopaba dá um depoimento de vida. Foi uma mulher negra e lésbica e ela também abordou questões de negritude. Então teve questões étnicas. Foi muito bom e foi emocionante porque ela trouxe relatos muito fortes, de agressões, por ela ser negra lésbica mulher. Foi emocionante. Foi bonito. (Vanessa Elias, 2017).

\section{A invisibilidade da religiosidade africana e afro-brasileira}

Foi um trabalho da disciplina da Geografia no $8^{\circ}$ Ano. [...]. Então, eu fiz uma feira ali também. Uma coisa que me chamou muita atenção foi sobre a religiosidade. Infelizmente, ainda há um preconceito gigantesco, e eu lembro que o menino me falou: "professora, pelo amor de Deus não me põe no grupo de religiosidade porque eu morro de medo.” Essa feira foi bem interessante e não foram só questões culturais naquele momento. Eu trouxe algumas questões temáticas referentes à questão negra. Então, não me lembro de tudo ao certo, mas eu lembro que pedi para as meninas trabalharem a questão da mulher negra. Foi dado enfoque mais a questão da mulher e também grandes mulheres e também grandes nomes de destaque da ciência e da literatura negras. E principalmente brasileiros, mas também do mundo, porque existe a invisibilidade de autores, escritores, de artistas negros na nossa sociedade. Então eu pedi para eles 
fazerem. Deixei bem livre e aí teve exposição de fotografia, teve dicionários, teve bastante coisa assim, bem diferente, comida e tal e foi bem bonita. (Vanessa Elias, 2017)

A colonialidade do ser aparece nesta narrativa monadológica quando a professora Vanessa Elias narra que um dos resultados que foi muito interessante foi a atitude da estudante em querer se colocar como autora do processo. Isto demonstra o quanto é necessário que as populações negras, sejam eles/eles crianças, jovens, adultos ou idosos possam dizer de si, de suas experiências, de suas memórias, como no dizer de Djamila Ribeiro (2017) do seu lugar de fala. É preciso deixar que as pessoas negras, que por muitos séculos foram silenciadas nas escolas e nas salas de aula pelo racismo epistêmico, possam narrar aquilo que sentem e que vivenciam, que experimentam no seu cotidiano. Já o menino que pede que a professora não o inclua no grupo da religiosidade é porque ele está imbuído de uma concepção de religiões africanas e afro-brasileiras cunhadas como coisa diabólica, não cristã e, portanto, deve ser omitidas, esquecidas, silenciadas de qualquer ambiente e em especial do ambiente escolar.

\section{Uma conversa que aponta caminhos para outras/novas conversas}

Diante desses relatos e de tantos outros nas escolas do Brasil, conforme pesquisas como as de Oliveira (2010), Santos (2010), Dias (2011), Pereira (2011), Paula (2013), Borges (2014), Passos (2014) indicam a existência de preconceito, discriminação e racismo contra as populações africanas e afro-brasileiras nos provocam a reflexão. Desse modo, precisamos romper com a colonialidade do poder, do saber e do ser. E caminhar para a desconstrução/problematização do pensamento racional eurocêntrico que se afirmou historicamente como o único parâmetro de saber e de sociedade e tem permeado o ambiente acadêmico das universidades, das legislações, do espaço escolar, da mídia, enfim, do sistema educativo e social em múltiplas dimensões. Para realizarmos essa árdua tarefa, várias alternativas são propostas como a desconstrução radical e completa na sociedade brasileira da suposta democracia racial; a problematização e superação dos padrões da branquitude; Para tais mudanças faz-se necessário a construção de propostas pedagógicas/curriculares decoloniais e interculturais que dialoguem com todas as matrizes étnicas.

Para se superar efetivamente a colonialidade nos sistemas públicos e privados de ensino e efetivar a implementação da lei 10.639/2003 e uma efetiva educação para as relações étnicoraciais devemos descolonizar os currículos (GOMES, 2012). Para tal precisamos trazer para o cenário educacional as histórias e culturas africanas, afro-brasileiras e indígenas e 
consequentemente por meio desses temas debater e problematizar o histórico racismo presente em nossa sociedade. Neste sentido, faz-se urgente e necessário que os pressupostos da interculturalidade rompam com as epistemologias eurocentradas e que seja acompanhado por novos procedimentos didático-metodológicos.

Na educação, sobretudo e, na educação para as relações étnico-raciais, em especial, apesar de vislumbramos alguns avanços no trato com as diferenças, com as diversidades e com princípios epistemológicos diferentes do europeu, mesmo assim precisamos avançar muito. Nossos currículos, nossos planos de ensino, nossas aulas compartimentadas ainda privilegiam um tipo de estudante, um tipo de organização curricular que ainda é de matriz colonial eurocêntrica autoritária, patriarcal, heteronormativa e cristã. Quantos conhecimentos ainda faltam nas nossas universidades, nos cursos de formação, na mídia impressa e falada, nos livros didáticos sobre as epistemes dos indígenas, dos quilombolas, dos afro-brasileiros? Quantos conhecimentos ainda precisamos adquirir para que possamos nos decolonizarmos efetivamente? Como ensinar e estudar história da África para além da Europa?

Vimos pelos questionamentos acima que estudar a cultura afro-brasileira e, em especial, a história do continente africano para cumprirmos a lei e as Diretrizes tem se constituído verdadeiro campo de questionamentos no ensino de história, pois ainda não convivemos sequer com um consenso entre os especialistas de como abordar esse ensino.

Portanto, pensamos que uma das metodologias adotadas em sala de aula que poderá atender a demanda da educação das relações étnico-raciais e de ensino de história e cultura africana e afro-brasileira pode ser a interculturalidade. Esta, pressupõe que determinados procedimentos didático-metodológicos poderão vir acompanhados de um rompimento com as epistemologias eurocentradas se adotarmos os referenciais teóricos da interculturalidade critica, que “opõe-se ao sistema político e econômico neoliberal e considera a educação intercultural como direito e meio para contribuir com a transformação da condição subalterna das minorias”. (SILVA; FERREIRA; DA SILVA, 2013, p.258).

Por interculturalidade defendemos um estilo de vida e de convívio com as diversas culturas que compõe o espaço escolar, mas a educação intercultural vai além do simples convívio. Ela pressupõe respeito, partilha, harmonia, diálogo entre docentes, estudantes e demais componentes do ambiente escolar, nas suas mais diferentes identidades: de gênero, sexo, etnia, geracional, religiosa, etc. 
Para se pensar uma educação decolonial, deve-se compreender a interculturalidade para além de um novo enfoque pedagógico, i é, como um “processo e projeto político” (OLIVEIRA, 2010, p.25). Projeto político este que pode se aproximar com a Lei 10.639/2003 bem como as Diretrizes Curriculares Nacionais para a Educação das Relações Étnico-raciais e para o Ensino de História e Cultura Afro-brasileira, Africana e Indígena. Para tanto, estamos amparados na Lei e nas Diretrizes, as quais propõem que se aborde em salas de aula - e agora como obrigatoriedade - as histórias e culturas africanas, afro-brasileiras e indígenas, pautados em outras lógicas, bem como outras formas de ensino-aprendizagem descentrado da matriz eurocêntrica, contemplando as populações africanas, afro-brasileiras e indígenas. Portanto, o professor ao desenvolver outras práticas pautadas em paradigmas diferentes das do mundo europeu e trazendo outras perspectivas educacionais e formulando epistemologias outras, tem a possibilidade de criar espaços epistemológicos interculturais e pedagogias decoloniais diferentes da eurocentradas. Paim (2019) nos oferece algumas possibilidades de práticas pedagógicas decoloniais a partir dos questionamentos de pressupostos coloniais e eurocentrados e nos propõe

buscar a desconstrução das metanarrativas sobre a modernização, racionalização e progresso procurando restaurar as vozes, as experiências, as identidades, as histórias dos subalternos e a importância das comunidades periféricas, as memórias coletivas, articular o sensível e o conceitual; desfazer a cultura do silêncio, as contradições opressor-oprimido rearticulando-as para superação das marcas profundas da colonialidade inscrita na memória social dos povos colonizados; o pensamento atuará como um semeador que semeia ideias e premissas prenhes de indignação e esperança num mundo onde a vida seja a fonte, centro e fim da cultura de cuidado com o outro; romper com a invisibilidade dos ditos conhecimentos populares, leigos, plebeus, camponeses, ou indígenas parando de tratá-los como crenças, opiniões, magia, idolatria, entendimentos intuitivos ou subjetivos; romper com a dicotomização que coloca de um lado a ciência, a filosofia e a teologia e, de outro, como menores e desqualificados, todos os conhecimentos que não seguem a racionalidade e cientificidade; pautar-se numa epistemologia que abrange todos os saberes estabelecendo as condições da sua produção e validação sem hierarquização; não desqualificar nenhum saber, embora considerando diferenças entre eles incluindo-os num repertório alargado de "ciências" ou de saberes científicos; definir-se por pensamentos de fronteira como resposta crítica aos fundamentalismos exige um pensamento mais amplo que o cânone ocidental (incluindo o cânone ocidental de esquerda) e assim estabelecer um diálogo crítico entre os diversos projetos políticos/éticos/epistêmicos, apontados a um mundo pluriversal; levar a sério as perspectivas/cosmologias/visões de pensadores a partir de corpos e lugares étnicoraciais/sexuais subalternizados; lutar contra uma monocultura do saber, não apenas no campo teórico, mas na prática constante dos processos de investigação; lutar contra o desperdício da experiência que o ocidente impôs ao mundo pela força.

Esta citação, embora um tanto extensa, nos provoca a pensar procedimentos didáticometodológicos para (re) pensarmos nossas práticas em sala de aula nas mais diversas áreas do 
conhecimento e na história em particular. Como por exemplo, pensar nas possibilidades de levar para sala de aulas explicações de determinados temas históricos numa perspectiva negra ou indígena; trazer referenciais de mulheres negras e indígenas como um dos pressupostos da decolonialidade para as aulas; utilizar como fontes diversos textos e gênero literários para além do livro didático como romances de época, textos de jornais, poesias, narrativas orais do passado e de pessoas do presente como os remanescentes de quilombos, entre outras.

O professor irá contemplar em suas aulas, em seu planejamento anual ou em seu plano de ensino, outras histórias e outras subjetividades que poderão favorecer a autoestima e a autoafirmação de populações subalternizadas como de afro-brasileiros e indígenas. Com isso, acreditamos dar um passo a mais no ensino de História e cultura africana, afro-brasileira e indígena vinculados à educação para as relações étnico-raciais, por meio de uma proposta de educação que se encaminhe para a promoção de uma sociedade mais justa, menos desigual, praticando assim os encaminhamentos propostos nos documentos oficiais.

\section{Referências bibliográficas}

ALMEIDA, Silvio Luiz de. O que é racismo estrutural. Belo Horizonte: Minas Gerais: letramento, 2018.

BENJAMIN, Walter. A origem do drama barroco alemão. São Paulo: brasiliense, 1984. BENJAMIN, Walter. Magia e técnica, arte e política. Obras escolhidas - ensaios sobre literatura e história da cultura. V. I. 8a ed. rev. São Paulo: Brasiliense, 2012. pp. 123 - 128. BRASIL, Lei 10.639/2003, de 09 de janeiro de 2003. Disponível em https://www.planalto.gov.br/ccivil_03/leis/2003/L10.639.htm. Acesso em 21/11/2016. BRASIL, Diretrizes Curriculares Nacionais para a Educação das Relações Étnicorraciais e para o Ensino de História e Cultura Afro-brasileira e Africana. Brasília: Distrito Federal, outubro, 2005. Disponível em http://www.acaoeducativa.org.br/fdh/wpcontent/uploads/2012/10/DCN-s-Educacao-das-Relacoes-Etnico-Raciais.pdf BRASIL, Lei de Diretrizes e Bases da Educação Nacional, nº 9394/96, de 20 de dezembro de 1996. In: SINEPE/SC- Sindicato das Escolas Particulares de Santa Catarina - livreto, $12^{\circ}$ edição, Florianópolis, 2010

BARBOSA, Muryatan Santana. Eurocentrismo, História e História da África. Sankofa: revista de História da África e de Estudos da diáspora africana. São Paulo: NEACP, n ${ }^{\circ}$, ano 1, pp. 46 - 53, jun/2008.

BORGES, Jorgeval Andrade. A vez da História da África? O ensino de história africana em escolas públicas da Bahia. Tese (Doutorado em Educação). Universidade Federal da Bahia. Faculdade de Educação. Salvador, 2014. 316 f.

CARVALHO, Silvia Cristina de Sousa. Eurocentrismo e racismo: o fetiche nas relações sociais na sociedade capitalista. Ser Social. Brasília. Vol. 19, nº 41. p. 296 -313. Jul. dez./2017.

CERQUEIRA, Daniel, LIMA, Renato Sérgio de; et al. Atlas da Violência 2017. Rio de Janeiro: IPEA e FBSP, 2017. 
COSTA, Cândida Soares da. Educação para as relações étnico-raciais: planejamento escolar e literatura no ensino médio. Cuiabá: Editora da UFMT, 2011, 284 p.

GALZERANI, Maria Carolina Bovério. Memória, História e tempo: perspectivas teóricometodológicas para a pesquisa em ensino de história. Cadernos Ceom. Ano 21, n 28 , jun/2008, p. 15-32.

GALZERANI, Maria Carolina Bovério. Políticas de ensino em projeto de educação patrimonial: a produção de saberes educacionais. Pro-posições, vol. 24, $n^{0}$ 1, jan/abr/2013, pp. $93-107$.

GOMES, Nilma Lino. Relações étnico-raciais, educação e descolonização dos currículos. Currículo sem fronteiras. Vol. 12, n ${ }^{0}$ 1, jan./abril. 2012, pp. 98 -109.

LARROSA, Jorge. Tremores: escritos sobre experiência. Belo Horizonte: Autêntica editora, 2017.

MATOS, Olgária Chain Feres. Os arcanos do inteiramente outro: a escola de Frankfurt, a melancolia e a revolução. $2^{\mathrm{a}}$ ed. São Paulo: brasiliense, 1989. 357 p.

OLIVEIRA, Luiz Fernandes. História da África e dos africanos na escola: as perspectivas para a formação dos professores de história quando a diferença se torna obrigatoriedade curricular. Tese (Doutorado em Educação). Departamento de Educação do Centro de Teologia e Ciências Humanas. Pontifícia Universidade Católica do Rio de Janeiro. Rio de Janeiro, 2010. $281 \mathrm{f}$.

OLIVEIRA, Luiz Fernandes. História da África e dos africanos na escola: desafios políticos, epistemológicos e identitários para a formação dos professores de História. Rio de Janeiro: Imperial Novo Milênio, 2012, 320 p.

PAIM, Elison Antônio. Memórias e experiências do fazer-se professor. Tese (Doutorado em Educação). Faculdade de Educação: Universidade Estadual de Campinas. Campinas, São Paulo, 2005. $532 \mathrm{f}$.

PAIM, Elison Antonio; PEREIRA, Pedro Mülbersted; FREIRE, Ana Paula da Silva. (Org.)

Diálogos com Walter Benjamin: memórias e experiências educativas. Florianópolis.

NUP/CED/UFSC, 2018. 344 p.

PAIM, Elison Antonio. Epistemologia decolonial: uma ferramenta para ensinar histórias outras. 19.06.2019. H Magazine: humanidades em rede. 2019. Disponível em https://hhmagazine.com.br/epistemologia-decolonial-uma-ferramenta-politica-paraensinar-historias-outras/. Acesso em 26.07.2019.

PASSOS, Flávio José dos. A urgência de um processo de desconstrução do racismo institucional: uma proposta didático-pedagógica. Educação, Gestão e Sociedade: revista da faculdade Eça de Queirós. Ano 1, nº 2, p.1 - 19, 2011.

PASSOS, Joana Célia dos. As relações étnico-raciais nas licenciaturas: o que dizem os currículos anunciados. Poiésis. Revista do Programa de Pós-graduação em Mestrado em Educação. Vol. 8, nº13, p. 172 - 178, jan/jun. 2014.

PAULA, Benjamim Xavier de. A educação para as relações étnico-raciais e o estudo da história e cultura da África e afro-brasileira: formação, saberes e práticas educativas. Tese (Doutorado em Educação). Faculdade de Educação - FACED. Universidade Federal de Uberlândia. Uberlândia, MG, 2013. 327 f.

PEREIRA, Amilcar Araújo. “O mundo negro”: a constituição do movimento negro contemporâneo no Brasil (1970 - 1995). Tese. (Doutorado em História). Instituto de Ciências Humanas e Filosofia: Universidade de São Paulo. São Paulo, 2010, 268 f.

PEREIRA, Paula de Abreu. A educação das relações étnico-raciais: experiência numa escola pública de Santa Catarina. Dissertação (Mestrado em Educação). Centro de Ciências da Educação. Universidade Federal de Santa Catarina. Florianópolis, 2011. 318f. 
QUIJANO, Anibal. Colonialidad del poder y classificação social: CASTRO GOMES, Santiago; GROSFOGUEL, Ramón. (Orgs). El giro decolonial: reflexiones para una diversidad epistémica, mas allá del capitalismo global. Bogotá: Universidade Javeriana Instituto Pensar/Universidade Central - IESCO/Siglo del Hombres editores, 2007, pp. 93 126.

RIBEIRO, Djamila. O que é lugar de fala? Belo Horizonte - Minas Gerais: letramento, 2017, $112 \mathrm{p}$.

SANTOS, Lorene dos. Saberes e práticas em redes de trocas: a temática africana e afrobrasileira em questão. Tese (Doutorado em Educação). Faculdade de Educação. Universidade Federal de Minas Gerais. Belo Horizonte, Minas Gerais, 2010. 334 f.

SILVA, Petronilha Beatriz Gonçalves e. Aprender, ensinar e relações étnico-raciais no Brasil. In: FONSECA, Marcus Vinicius, SILVA, Carolina Mostaro Neves da, FERNANDES, Alexandra Borges (Orgs.). Relações étnico-raciais e educação no Brasil. Belo Horizonte: Mazza edições, 2011, 216 p.

SILVA, Janssen Felipe da; FERREIRA, Michele Guerreiro; DA SILVA, Delma Josefa. Educação das relações étnico-raciais: um caminho aberto para a construção da educação intercultural crítica. In: Revista eletrônica da educação. vol. 7. nº 1. maio/2013, pp. 248 272.

SOUZA, Arivaldo Santos de. Racismo institucional: para compreender o conceito. Revista da $A B P N$, vol. 1, n. 3, pp. 77 - 87, nov. 2010 a fev. 2011.

TARDIF, Maurice. Saberes docentes e formação profissional. $17^{\mathrm{a}}$ ed. Petrópolis. Rio de Janeiro: Vozes, 2014.

WALSH, Catherine. (Org.). Pedagogías decoloniales: Prácticas insurgentes de resistir, (re)existir y (re)vivir. TOMO II. Quito: Abya Yala, 2017. 583p.

\section{Fontes orais}

ALBUQUERQUE, Mauricélia Teixeira de. [2017]. Entrevistador: Odair de Souza. Garopaba, SC, 14, out. 2017.

ELIAS, Vanessa. [2017]. Entrevistador: Odair de Souza. Garopaba, SC, 27, nov. 2017.

OLIVEIRA, Marilete Pinto de. [2017]. Entrevistador: Odair de Souza. Garopaba, SC, 20, nov. 2017.

MACHADO, Gilmar Gonçalves. [2017]. Entrevistador: Odair de Souza. Garopaba, SC, 13, nov. 2017.

\footnotetext{
${ }^{11}$ CAPETTI, Pedro; CANONICO, Marco Aurélio. Denúncia de ataques as religiões africanas crescem 47\% no país. O GLOBO - Sociedade. 25 de janeiro de 2019. Disponível em https://oglobo.globo.com/sociedade/denuncias-de-ataques-religioes-de-matriz-africana-sobem-47-no-pais23400711 . Acesso em 30/06/2019.

${ }^{2}$ Discriminação é o nome que se dá para a conduta (ação ou omissão) que viola direito de pessoas com base em critérios injustificados e injustos tais como raça, sexo, a idade, a opção religiosa e outros (Programa Nacional de Direitos Humanos, 1998, p. 13 apud SANT'ANA, 2008. p. 59).

3 Casos como a torcedora que ataca o goleiro Aranha com palavras ofensivas e racistas. https://www.youtube.com/watch?v=mAl3VTsuNOc. Acesso em 05 de março de 2016.

${ }^{4}$ Entende-se por desigualdade racial "toda situação injustificada de diferenciação de acesso e fruição de bens, serviços e oportunidade nas esferas pública e privada em virtude da raça, cor, descendência ou origem nacional ou étnica”. (artigo $1^{\circ}$, inciso $2^{\circ}$ da Lei $n^{\circ} 12.228$, de 20 de julho de 2010).

${ }^{5}$ La colonialidad es uno de los elementos constitutivos y especificos del pátron del poder mundial capitalista. Se funda en la imposicion de una classificacion racial/étnica de la problacion del mundo como pedra angular de dicho pátron de poder, y opera em cada uno de los planos, âmbitos e dimensiones materiales y subjetivas de La existência cotidiana y de La escala social. (QUIAJANO, 2007, p. 93)
} 


\begin{abstract}
${ }^{6} \mathrm{O}$ grupo é formado predominantemente por intelectuais da América Latina e apresenta um caráter heterogêneo e transdisciplinar, compondo seu grupo figuras como: Enrique Dussel, Anibal Quijano, Walter Mignolo, Rámon Grosfoguel, Catherine Wash, Nelson Maldonado - Torres, Arturo Escobar, entre outros. Tem como categoria de análise o conceito de decolonialidade, bem como o mito da fundação da modernidade, colonialidade (do poder, do saber e do ser), o racismo epistêmico, a geopolítica do conhecimento, a diferença colonial, o pensamento liminar, a transmodernidade e a interculturalidade crítica. (OLIVEIRA, 2012, p. 41)

${ }^{7}$ Mesmo antes da lei 10.639/2003, alguns municípios brasileiros já haviam homologado e publicado leis que exigiam a presença de histórias e culturas africanas e afro-brasileiras nos currículos escolares. Leis como as do Espírito Santo, Decreto ${ }^{\circ}$ 6.694, de $1^{\circ}$ de abril de 1996, que institui Grupos de trabalho Intersecretarial, com a finalidade de desenvolver políticas educacionais para a valorização do povo negro e dá outras providências; em Salvador (Bahia) o projeto de Lei n ${ }^{0}$ 374/91 instituiu a criação de curso preparatório para o corpo docente e outros especialistas da Rede Municipal de Ensino, visando a implantação de disciplinas ou de conteúdos programáticos no currículo da referida rede, baseado na cultura e na história do povo negro e indígena; Lei nº 4446/94 que instituiu a inclusão do conteúdo história afro-brasileira nos currículos das escolas municipais de Florianópolis.

${ }^{8}$ A Lei 10.639/2003, em 2008 sofreu modificações e incluiu em seu escopo legal as histórias e culturas dos povos indígenas, tornando-se assim a lei de $\mathrm{n}^{\mathrm{0}} 11.645 / 2008$.

${ }^{9}$ Especialização, com carga horária de 420 horas, promovida pela Universidade Federal de Santa Catarina (UFSC) com o nome de Gênero e Diversidade na Escola (GDE) no período de fevereiro de 2015 a dezembro de 2016.
\end{abstract}

Recebido em 31/07/2019.

Aceito em 28/10/2019. 